\title{
Smoking ban in US hospitals presents new challenges
}

\author{
C Tracy Orleans, John Slade
}

From 1 January 1992 hospitals in the United States applying for accreditation by the Joint Commission on the Accreditation of Healthcare Organisations (JCAHO) are required to develop and implement a policy to prohibit smoking among patients, visitors, employees, volunteers, and medical staff. ${ }^{1}$ Any exceptions must be "defined in written criteria that are developed and approved by the medical staff and authorised for individual patients by physician order." While this regulation represents substantial progress, it deals directly only with the problems of pollution by tobacco smoke, leaving the issue of whether and how to manage nicotine dependence among inpatients up to individual institutions.

The new rule greatly expands the previous JCAHO standard, which required only that hospitals have and enforce a policy "discouraging" smoking. Hospitals have up to 24 months to demonstrate full compliance, but, in the interim, they must restrict smoking to "a designated location(s) that is separate from all inpatient and outpatient care areas."

This new standard will affect some 5000 hospitals and 560 psychiatric institutions, approximately $80 \%$ of all hospitals in the United States. JCAHO approval is critical for these institutions, bearing on their reimbursements from Medicare and other insurers as well as on their state licences, bond ratings, and ability to attract staff. ${ }^{2}$ Though $90 \%$ of US hospitals have restricted smoking, usually in response to statewide legislation, fewer have imposed total smoking bans..$^{3-5}$ Although some states, such as Minnesota and New Jersey, already require hospitals to be smoke-free by law or by regulation, a survey by the American Hospital Association in 1987 found that only $16 \%$ of more than half of its 6500 member institutions responding to a survey had enacted total smoking bans. ${ }^{6}$

The ban has the potential to foster important changes in smoking by employees and patients. The JCAHO recommends that an implementation plan "may include the offering of a smoking cessation support program to those staff members and employees who wish to stop smoking."1 A hospital smoking ban introduced with such services can result in significant reductions in the prevalence of smoking among employees and in the daily smoking rate in all employee groups. ${ }^{4}$ In our view, such services should not only be offered but also be an ongoing employee benefit and not merely part of a transition to the new policy.
Unfortunately, the new JCAHO rule does not require hospitals to help patients stop smoking. For patients admission to hospital represents a critical health care incident and "teachable moment," when perceived vulnerability to smoking related health harms and responsiveness to medical advice to stop smoking are likely to be at their peak. While the prevalence of smoking in inpatients is not known precisely, in 1989 there were over 25 million short term hospital admissions among adults (Robin Swanson, American Hospital Association, personal communication), and the national prevalence of smoking among adults is estimated at $26 \%$. As Louise Nett has pointed out, these data suggest that a sizable fraction of the nation's 50 million smokers could be reached each year through hospital based programmes (paper presented at workshop at the meeting of the American College of Chest Physicians, Northbrook, Illinois, December 1991).

Minimal contact nicotine addiction treatment programmes during an admission to hospital can help patients turn enforced, short term abstinence into permanent cessation. Several studies have shown that even brief, once only bedside consultations with smokers who are inpatients and have been referred by a physician can produce sustained rates of stopping smoking of $25-30 \%{ }^{7-10}$ - rates that are equivalent to those produced by more intensive, formal clinics with motivated, self referred quitters. ${ }^{11}$ The recent introduction of transdermal nicotine replacement in the United States may help to make hospital based treatments even more effective. ${ }^{12}$

Hospitals often are reluctant to add a service such as this unless its costs can be recovered. When run by independent health professions, however, such a service can be self sustaining. ${ }^{8}$ If state or federal regulatory authorities decide that this is a worthwhile service to make available to inpatients, hospitals would be able to include the cost of the service in their rates for reimbursement. This step would represent significant progress towards achieving health insurance coverage for nicotine dependence in the United States. ${ }^{13}$

The greatest controversy the new rule will generate is likely to be over whether patients admitted to psychiatric or chemical dependency units should be given exemptions from the ban by their physicians. While some of these units already have adopted smoke-free policies after careful planning and implementation, ${ }^{514-16}$ others have been reluctant because 
of fears that patient management would be more difficult and that underlying conditions might worsen. ${ }^{217}$ Drug abuse and psychiatric units which have become smoke-free have generally experienced much less difficulty than anticipated, however, and they have generally been pleased with the changes.

The new rule places responsibility for smoking by a patient in the hands of the attending physician, just as orders for diet, activity, and the prescription of other drugs are at present. While physicians will frequently have the option to permit smoking by patients, doing so will now require an affirmative action on their part for each patient granted this exemption.

To facilitate compliance with the new JCAHO policy, the American Hospital Association is offering several publications, including a 47 page public relations resource package entitled Smoking and Hospitals Are a Bad Match, which outlines how to plan, communicate, and implement a smoke-free policy, and a 10 page booklet, Smokefree Hospital Patient Communication and Staff Training Resources, describing how to organise and staff patient quit smoking services, even when the provision of clinical services is not required. Both can be obtained from the American Hospital Association (840 N Lake Shore Drive, Chicago, Illinois 60611 (tel 800242-2626)). The National Heart, Lung and Blood Institute guide How You Can Help Your Patients Stop Smoking: Opportunities for Respiratory Care Practitioners provides detailed guidance in organising and implementing bedside nicotine addiction treatment programmes through respiratory care departments. ${ }^{18}$ This publication can be obtained from the National Heart, Lung and Blood Institute, Education Programs Information Center, 44733 Bethesda Avenue, Suite 530, Bethesda, Maryland 20814 (tel 301-851-3260).

Clearing the air in hospitals is a substantial, essential step. This new regulation is in line with the current understanding of how harmful tobacco smoke pollution is for nonsmokers. ${ }^{19-21}$ It puts in effect the steps which must be taken to afford those who do not smoke the same degree of protection from this pollutant as governmental practice commonly requires in the case of other pollutants. ${ }^{22}$ The next challenge hospitals face in this area is working out how to manage nicotine dependence among their inpatients. Fortunately, sound approaches to facilitate this step are available.

1 Joint Commission on the Accreditation of Healthcare Organisations. Hospital standards 1992. Chicago: Join Commission on the Accreditation of Healthcare Organisations, 1991.

2 Associated Press. Hospitals fear smoking ban will disturb some patients. The Times (Trenton, New Jersey) 1991 Dec 28: A-7.

3 Hurt RD, Berge KG, Offord KP, Leonard DA, Gerlach DK, Larson Renquist C, et al. The making of a smokefree medical center. $7 A M A 1989 ; 261: 95-7$.

4 Stillman FA, Becker DM, Swank RT, Hantula D, Moses $\mathrm{H}$, Glantz S, et al. Ending smoking at the Johns Hopkins $\mathrm{H}$, Glantz $\mathrm{S}$, et al. Ending smoking at the Johns

5 Joseph AM, O'Neil PJ. The Department of Veteran Affairs smoke-free policy. $\mathcal{F} A M A$ 1992; 267:87-90.

6 American Hospital Association. Final report: census of hospital-based health promotion and patient education programs. Chicago: American Hospital Association, Division of Ambulatory Care and Health Promotion, 1988.

7 Hurt RD, Lauger GG, Offord KP, et al. An integrated approach to the treatment of nicotine dependence in a medical center setting: description of the initial experience. $\mathcal{F}$ Gen Intern Med (in press)

8 Orleans CT, Rotberg H, Quade D, Lees P. A hospital quitsmoking consult service: clinical report and intervention guidelines. Prev Med 1990; 19: 198-212.

9 Stevens VJ, Glascow RE, Lichtenstein E, et al. Smoking intervention for hospital patients. Proceedings of the annual meeting of the American Public Health Asannual meeting of the American

10 Taylor CB, Houston-Miller N, Killen JD, DeBusk RF. Smoking cessation after acute myocardial infarction: effects of a nurse-managed intervention. Ann Intern Med 1990; 113: 118-23.

11 US Department of Health and Human Services. Reducing the health consequences of smoking - 25 years of progress. A report of the Surgeon General. US Department of Health and Human Services, Public Health Service, Centers for Disease Control, Center for Chronic Disease Prevention and Health Promotion, Office on Smoking and Health, 1989. (DHHS Publication No (CDC) 89-8411.)

12 Transdermal Nicotine Study Group. Transdermal nicotine for smoking cessation. $\mathcal{F} A M A 1991$; 266 : 3133-8.

13 Institute for the Study of Smoking Behavior and Policy. Smoking cessation - the organization, delivery, and finanSmoking cessation - the organization, delivery, and finan-
cing of services. Hollis, New Hampshire: Puritan Press, 1990

14 Resnick MP, Bosworth EE. A smoke-free psychiatric unit. Hosp Community Psychiatry 1989; 40 : 525-7.

15 Joseph AM, Nichol KL, Willenbring ML, Korn JE, Lysaght LS. Beneficial effects of treatment for nicotine dependence during an inpatient substance abuse treatment program. FAMA 1990; 263: 1581-3.

16 Hoffman AL, Slade J. Following the pioneers: addressing tobacco in chemical dependency treatment. $\mathcal{F}$ Subst Abuse Treat (in press).

17 Glassman AH, Helzer JE, Covey LS, Cottler LB, Stetner F, Tipp JE, et al. Smoking, smoking cessation, and major depression. $₹ A M A$ 1990; 264: 1546-9.

18 US Department of Health and Human Services. How you can help patients stop smoking: opportunities for respiratory
care practitioners. Washington, DC: National Heart, Lung and Blood Institute, 1989. (NIH Publication No 89-2961.)

19 US Department of Health and Human Services. The health consequences of involuntary smoking. $A$ report of the Surgeon General. US Department of Health and Human Services, Public Health Service, Centers for Disease Control, 1986. (DHHS Publication No (CDC) 87-8398.) 20 Glanz S, Parmley W. Passive smoking and heart disease. Circulation 1991; 83: 1-12.

21 Steenland $\mathrm{K}$. Passive smoking and the risk of heart disease. FA.MA 1992; 267: 94-9.

22 Repace JL, Lowrey AH. An indoor air quality standard for ambient tobacco smoke based on carcinogenic risk. $N Y$ State 7 Med $1985 ; 85: 381-3$. 